\title{
South Africa's Child Support Grant and the dignity of female caregivers
}

\author{
The Child Support Grant is social assistance paid for children living with \\ low income caregivers. The experiences of applying for the grant, using the \\ grant, and being a grant recipient were explored with almost two hundred \\ low income female caregivers in South Africa and the impact on dignity \\ was examined.
}

\section{Key points}

1. There is no social security for low income caregivers of working age in South Africa unless they are disabled. However many caregivers interact with the social security system as recipients of the Child Support Grant (CSG) for their beneficiary children.

2. The CSG plays a vital role in the lives of low income families and many studies have demonstrated its positive impacts. This study explores ways in which the recipients experience the CSG as protective or erosive of their dignity in order to identify ways to ensure that people's constitutional right to have their dignity protected and respected plays a central role in social security policy design and implementation.

3. The CSG was experienced by many caregivers as protective of dignity in three main ways: by reducing poverty, by helping them to fulfil the role of looking after their children, and more indirectly by enabling caregivers to use the grant in dignity-enhancing ways in their social networks.

4. However, the CSG was also experienced by many as erosive of dignity in three main ways: issues to do with the application process, negative societal attitudes towards CSG recipients, and the small amount of the CSG.

5. The balance of positive and negative experiences varied by recipient and context, reflecting the complexity of dignity as a lived phenomenon.

The research

By Gemma Wright, Michael Noble, Phakama Ntshongwana, David Neves and Helen Barnes. A collaboration between the Centre for the Analysis of South African Social Policy at the University of Oxford, the Institute for Poverty, Land and Agrarian Studies at the University of the Western Cape, and the Human Sciences Research Council.
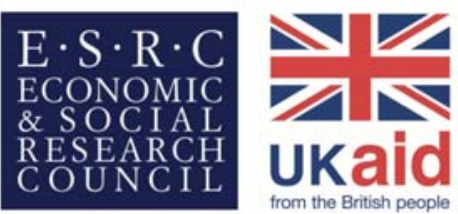

Research jointly supported by the ESRC and DFID

POLICY BRIEF 2 


\section{BACKGROUND}

The South African Constitution states that 'Everyone has inherent dignity and the right to have their dignity respected and protected'. How is the Child Support Grant experienced by female caregivers in practice, in terms of whether it helps to respect and protect their dignity?

\section{Methodology}

Thirty-six focus groups and 16 in-depth interviews were undertaken in the Eastern Cape and Western Cape in South Africa with low income female caregivers. Just under 200 women took part in the focus groups. Interviews were also held with senior policy makers in government, and social attitudes were explored more broadly in relation to dignity, poverty and social security using data from the HSRC's South African Social Attitudes Survey.

\section{The Child Support Grant}

The Child Support Grant (CSG) is social assistance for children with low income caregivers. It is currently paid at the rate of R310 per month and there are more than 11 million child beneficiaries. Almost all (98\%) of the caregivers are female. The CSG is administered by the South African Social Security Agency (http://www.sassa.gov.za). Qualifying requirements include: the primary caregiver must be a South African citizen, permanent resident or refugee; their income (and the income of their spouse if they have one) must fall below the means test threshold; the child/children must be under 18 years; children aged between 7 and 18 years must attend school; and both the applicant and the child must reside in South Africa. The caregiver and child need to register biometrically with SASSA: finger-prints are captured along with a voice recording and a photograph.

\section{Why focus on dignity?}

The Universal Declaration of Human Rights introduces the recognition of the inherent dignity of all people as a foundation of freedom, justice and peace in the world. Dignity plays a prominent role in South Africa's Constitution, both as a foundational value and a right. Dignity can also be considered as a psycho-social phenomenon and at times these two notions of dignity ('dignity as principle' and 'dignity in practice') may seem disconnected. In this study we explored the linkages by investigating the role that social security plays in relation to dignity in the lives of lone mothers in South Africa, in the context of their constitutional right to have their dignity protected and respected. Part of the study involved exploring the ways in which recipients of the CSG experience the grant as either respecting and protecting, or alternatively eroding their dignity.

\section{How do caregivers interact with the CSG?}

Although working-age caregivers of children are not entitled to social assistance in their own right (unless they are disabled) they do interact with the social security system in relation to the CSG. In this study the experiences of their interaction with the system and receipt of the CSG were explored in different three ways:

- As applicants of the CSG

- As 'users', custodians and consumers of the CSG for a beneficiary child

- In their status as CSG recipients, in the eyes of others 


\section{Three ways in which the CSG helps to protect and respect the dignity of female caregivers}

\section{Reducing poverty}

Recipients frequently described the CSG as a vital source of income and as such does help protect their dignity. Most tangibly, grant receipt served to elevate consumption and ameliorate poverty, and enable recipients to exercise a measure of individual agency.

"The CSG helps protect my dignity because without it I would have nothing, at all."

\section{Helping caregivers to fulfil the caregiver role}

The CSG helps protect caregivers' dignity by providing a regular income stream that assists caregivers with fulfilling their roles as caregivers of children.

"The CSG helps protect my dignity. It helps my child a lot even though I'm not working. When he's with other children he has some of the things that they have because of the grant."

\section{Strengthening practices of social reciprocity}

Grant receipt was also experienced as positive in relation to dignity in less direct ways, by strengthening practices of inter-dependency and mutuality between recipients and others in their kin and social networks. The indepth interviews yielded examples such as of CSG-receiving children being dispatched to urban kin to access superior quality schools, or left in the care of rural grandmothers as working age women sought jobs in urban labour markets.

\section{Three ways in which the CSG erodes the dignity of female caregivers}

\section{Issues with the application process}

SASSA has made great strides in promoting access to and take-up of the CSG. However, in almost all of the focus groups participants raised issues about ways in which the application process impacted negatively on their dignity. Women reported being made to feel unworthy by being required to queue for very lengthy periods, having to negotiate burdensome and unclear qualifying critieria, and of being treated disrespectfully by officials.

"You are sent from pillar to post, all the while you are starving, hunger written all over your face, where's the dignity in that?"

\section{The small amount of the grant}

The amount of the CSG has been increased incrementally and is regarded as part of a broader package of support for poor people, but many of the participants raised concerns about the adequacy of the grant. The point was repeatedly made that whilst the CSG helps and is 'better than nothing', it is not enough. Some went so far as to say that the CSG does not protect their sense of dignity at all, as the amount of the grant is so small relative to their needs.

"What I'm saying is that the CSG does not protect my dignity, at all, it's not enough to do that for me or my children."

"When you sit down and consider dignity and social grants - well, the money is too little to, it does not meet the needs of our children. It's like government is looking down on our sense of dignity as poor people. It's our government, we voted them into power. We suffered under the apartheid government, now we continue to suffer because government is not looking after us as citizens well. That's all I want to say." 


\section{Being the object of people's prejudices and judgements as a CSG recipient}

The prominence of the dependency culture discourse in popular consciousness, the media and even some parts of the state, as well as empirically unsubstantiated concerns that women are becoming pregnant in order to receive the CSG, causes some female CSG recipients to be at the receiving end of other people's prejudices. This was experienced by some as erosive of their dignity.

"I'm just going to speak as I see it or according to my experience because you said there is no wrong answer. I think it's crucial for people's dignity to be protected, especially women, young and old. For example, the fathers of our children don't support them, that's an indignity. The CSG can both protect and erode your dignity. It helps with the children on the one hand, but there's [...] people my age with jobs, that do not need the CSG, they tend to undermine one, you know, look down on us. That affects my dignity, negatively." "We need this grant but it comes at a very high cost, it costs us our dignity at the end of the day."

\section{Conclusion}

The CSG was found to be helpful in protecting dignity: it is a vital contribution to the cost of raising a child, it helps to reduce poverty, helps caregivers to fulfil their roles as caregivers, and even strengthens women's position within their kin and social networks. However some women described ways in which they experience the CSG as detrimental to their dignity, particularly in relation to aspects of the application process, negative attitudes towards them as CSG recipients within their communities, and the small size of the grant.

\section{About the project}

A group of researchers from the Centre for the Analysis of South African Social Policy at the University of Oxford in the UK, the Institute for Poverty, Land and Agrarian Studies at the University of the Western Cape in South Africa, and the South African Human Sciences Research Council undertook a research project between 2011 and 2014 entitled 'Lone Mothers in South Africa - The role of social security in respecting and protecting dignity'. It was funded by the Economic and Social Research Council and the UK Department for International Development (ESRC Ref ES/I033130/1).

\section{For further information}

- Policy Brief 1: Poverty erodes dignity: perspectives of low income female caregivers in South Africa

- Policy Brief 3: The Role of Social Security in Respecting and Protecting the Dignity of Lone Mothers in South Africa: Summary of Findings and Recommendations

The full report, The Role of Social Security in Respecting and Protecting the Dignity of Lone Mothers in South Africa: Final Report by Gemma Wright, Michael Noble, Phakama Ntshongwana, David Neves and Helen Barnes, is available at http://www.casasp.ox.ac.uk/docs/Dignity final report 120714.pdf. Or for further information contact Dr Gemma Wright by email gemma.wright@saspri.org or phone +27

(0)218136435.
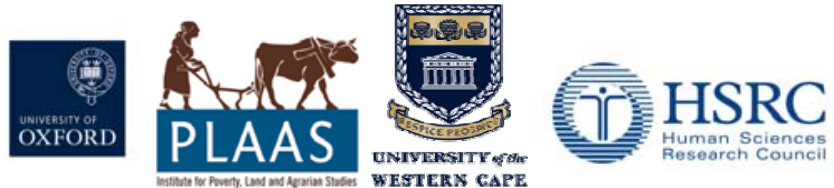